\title{
Banca y agricultura en el Perú antes de la guerra con Chile, 1866-1879
}

Recibido: 30/03/2021

Aprobado: 30/06/2021

Publicado: 31/07/2021

\author{
MARCO ANTONIO DE LA TORRE ZEVALLOS \\ Universidad Nacional Federico Villarreal (UNFV) \\ Universidad Nacional Mayor de San Marcos (UNMSM) \\ Correo: marcodltz11@outlook.com \\ ORCID iD: https://orcid.org/0000-0002-8473-8517
}

\section{RESUMEN}

El objetivo del presente artículo es mostrar la importancia del Banco de Crédito Hipotecario en el resurgimiento de la agricultura de exportación en el Perú antes de la guerra con Chile. Dicho banco es considerado el primero en ser creado para financiar las actividades productivas como la agricultura de exportación, en tiempos improductivos donde la economía peruana dependía y giraba en torno a las exportaciones del guano. El artículo también busca demostrar que la burguesía mercantil y bancaria, criticada de ser simple rentista que vivía a expensas del Estado peruano, invirtió sus capitales en entidades financieras como el $\mathrm{B}$ anco de Crédito Hipotecario para financiar el de sarrollo del país a través de actividades productivas como la agricultura de exportación que pudieran generar ingresos y evitar la dependencia fiscal de las exportaciones del guano.

Palabras clave: Banco, agricultura de exportación, burguesía, guano, Estado.

\section{Banking and Agricultura in Peru before the war with Chile, 1866-1879}

\begin{abstract}
The objective of this article is to showcase the importance of the Banco de Crédito Hipotecario in the resurgence of export agriculture in Peru before the war with Chile. This bank is considered the first to be created to finance productive activities, such as export agriculture, in unproductive times when the Peruvian economy depended and revolved around guano exports. The article also seeks to demonstrate that the mercantile and banking bourgeoisie, criticized for being simple rentiers who lived at the expense of the Peruvian State invested their capital in financial institutions, such as the Banco de Crédito Hipotecario, to finance the development of the country through productive activities such as export agriculture that could generate income and avoid fiscal dependency on guano exports
\end{abstract}

Keywords: Bank, agriculture, export, bourgeoisie, guano, State. 
H 1 decreto dictatorial del 31 de enero de 1866 firmado por el jefe provisorio de la república, Mariano Ignacio Prado, publicado en el diario oficial El Peruano, sorprendió y entusiasmó a muchos agricultores y propietarios de Lima. Se trataba de la autorización de bases dictadas para el establecimiento de una entidad financiera privada en Lima, con el nombre de Banco de Crédito Hipotecario, cuya finalidad sería facilitar préstamos a largo plazo, máximo 20 años, sobre hipotecas de fundos rústicos y urbanos. El objetivo era, a través de estos préstamos, aumentar el valor de la propiedad territorial y lograr el progreso de la agricultura mediante la modernización de los fundos rústicos. El establecimiento de este nuevo banco - el cuarto después de La Providencia, Banco del Perú y el Banco de Londres - se diferenciaba del resto por ser el primero en el Perú con fines de financiamiento y desarrollo económico a través del crédito.

A partir de la segunda mitad de la década de 1840, la situación económica y fiscal del Perú empezó a mejorar con las exportaciones del guano al mercado exterior. Por otro lado, las guerras civiles entre caudillos se hicieron menos frecuente, y con el ascenso político de Ramón Castilla, la situación política se estabilizó. En un contexto nuevo, de estabilidad política y mejora fiscal y económica, el guano sería el que generaría los capitales necesarios para la reactivación de la agricultura de exportación. Durante los períodos de Castilla y Echenique, entre los años 1845-1862, el Estado peruano creó los mecanismos necesarios para trasladar buena parte de los ingresos obtenidos por la exportación del guano al grupo de comerciantes y propietarios que habían sido golpeados económicamente por las guerras de independencia. Los mecanismos que empleó el Estado para trasladar estos capitales fueron una serie de medidas que aprobó el Ejecutivo, como la Ley de Inmigración de 1849 (Ley Chinesca), que comprometía al Estado a pagar al empresario con 30 pesos por cada chino coolie que introducía al país; la Ley de Consolidación de 1850, que obligaba al Estado a cancelar la deuda que se tenía con los acreedores nacionales, deuda contraída desde las guerras de independencia; la Ley de Manumisión de Esclavos de 1854, que comprometía al Estado pagar al hacendado o propietario 300 pesos por la libertad de cada esclavo; y la Ley de Consignación de 1862, por la que el Estado entregaba en exclusividad al grupo nacional de consignatarios encabezado por Manuel Pardo el negocio del guano al mercado inglés,

Durante los años de la década de 1860, ese mismo grupo de comerciantes y propietarios que fueron favorecidos por las leyes de consolidación y manu- 
misión, aprobadas por el Estado, empieza a fundar los primeros bancos comerciales, creados con la finalidad de financiar sus operaciones guaneras. La mayoría de los bancos que aparecieron en los años de la década de 1860 fueron creados con la finalidad de proporcionar el capital necesario para el gasto de las operaciones guaneras (mano de obra, maquinarias para la extracción, carguío), como fue el caso del Banco del Perú, creado en 1863. El Banco de Crédito Hipotecario se diferenciaba del resto de los bancos por ser el primero en el Perú con fines de financiamiento y desarrollo económico a través del crédito al proporcionar capitales a la agricultura. En enero de 1866, Mariano I. Prado autorizó, mediante decreto, a la cartera del ministro de Hacienda Manuel Pardo "[...] el establecimiento de una sociedad anónima con el título de Banco de Crédito Hipotecario que tenga por objeto facilitar los préstamos a largo plazo sobre hipotecas de fundos rústicos o urbanos y su reembolso por medio de anualidades comprensivas del interés y la amortización" (El Peruano 31-01-1866). Sería la primera entidad financiera pública que "[...] fomentaría la propiedad territorial que hoy permanece improductiva por falta de capitales que la fomenten" (El Peruano 01-06-1866).

El Banco de Crédito Hipotecario, que logró reunir un capital inicial de 1 500000 de soles, estuvo conformado por accionistas que eran integrantes de la nueva elite de poder en el Perú que se formó en la coyuntura del guano, y estuvo compuesta por comerciantes, intelectuales, propietarios y hacendados. Muchos de ellos fueron beneficiados por las leyes de consolidación, manumisión y consignación. La creación del Banco de Crédito Hipotecario es una demostración del interés que tuvo aquella nueva elite en fomentar e invertir en actividades productivas como la agricultura, dado que durante muchos años la historiografía peruana había señalado a esta nueva elite como "rentista y parasitaria“, que vivía a expensas del Estado.

Por otro lado, también hay que tener en cuenta las condiciones y factores externos que facilitaron el despegue del sector agrícola algodonero en los años de la década de 1860, y luego el azucarero en la década de 1870. Según los estudios de Bonilla (1974), durante los años 1865 y 1873, el desarrollo y despegue de estos sectores agrícolas (algodonero y azucarero) en la costa peruana no hubiera sido posibles de no existir en aquellos momentos condiciones extremadamente favorables en el mercado internacional, debido a la caída de la producción algodonera como consecuencia de la guerra civil norteamericana, entre los años 1861-1865, y la caída de la producción de azúcar por la crisis del Caribe, entre los años 1868-1878. 


\section{Material y métodos}

El tipo y diseño del estudio es explicativo y cuantitativo. Se emplean cuadros estadísticos y gráficos que permiten conocer las cantidades de dinero o cédulas prestadas por el banco, balances, operaciones, relación de accionistas, prestatarios, haciendas y también cuadros y gráficos de las exportaciones de azúcar y algodón. Se revisó, en la Hemeroteca de la Biblioteca Nacional, periódicos de la época como El Peruano, en los cuales se pudo hallar los decretos del Ejecutivo que ordenaba la creación del Banco de Crédito Hipotecario. Además, se halló también los estatutos que establecían el marco legal y las funciones del banco; y se encontró también la relación de nombres de los primeros accionistas fundadores del banco. Sumado a esto, se revisó las páginas del periódico El Nacional, en las cuales se pudo hallar memorias y balances de las operaciones de los primeros años de funcionamiento del Banco de Crédito Hipotecario, entregadas por los gerentes a los accionistas del banco. También se encontraron algunos informes y comunicados publicados en el periódico, dirigidos a los accionistas y público en general.

\section{La formación del capital agrario}

Después de muchos años de postración económica posindependentista, aparece en el Perú el guano. En 1840, son enviadas las primeras muestras de guano peruano a Europa, donde se producían transformaciones modernas en la agricultura, producto de la revolución agrícola e industrial, particularmente en Gran Bretaña. Debido a la fuerte demanda de aquellos países industrializados, las exportaciones del guano fueron aumentando año tras año, desde 1840 hasta la década de 1870. El guano mejoró las finanzas públicas y algunas actividades económicas, como la agricultura.

Los ingresos del Estado generados por las exportaciones del guano produjeron un profundo cambio en la estructura de las finanzas públicas en el Perú. Según los estudios de los especialistas como Shane Hunt (2011), el valor de todas las exportaciones de guano entre 1841-1878 fue de 763 millones de pesos; según Heraclio Bonilla (1974), de 750 millones de pesos. Esto representó más del $50 \%$ del total de los ingresos acumulados del Estado peruano entre los años 1846-1878 (Tantaleán 2011, 68), como se observa en la siguiente tabla: 
TABLA 1. Ingresos acumulados del Estado peruano (1846-1878)

\begin{tabular}{|l|c|c|}
\hline Guano & $54 \%$ & $60 \%(*)$ \\
\hline Empréstitos & $17 \%$ & \\
\hline Aduanas & $15,7 \%$ & $26 \%$ \\
\hline Salitre & $2,1 \%$ & $5 \%$ \\
\hline Contribuciones & & $9 \%$ \\
\hline Otros & $11,2 \%$ & \\
\hline
\end{tabular}

Fuente: Tantaleán (2011, 83 y 85)

(*) Según Contreras (1996)

El Estado peruano con el compromiso de saldar su deuda, tanto externa como interna, permitió el traslado de una buena cantidad de aquel dinero a un reducido sector de comerciantes y hacendados criollos a través de la ley de consolidación de 1850 (Castilla) y la conversión de los vales de deuda interna a externa durante el régimen de Echenique. El guano también permitió decretar la manumisión de esclavos, que también favoreció a un pequeño grupo de hacendados costeños, ya que la mayor cantidad de esclavos por las que se pagó por cada uno, la cantidad de 300 pesos, se hallaban en Lima y la costa norte. En efecto, ello permitió a la élite criolla costeña disponer de capitales para robustecer su posición en la actividad agrícola (Quiroz 1987, 159)

En este proceso de capitalización habría que considerar una parte de las utilidades percibidas por los consignatarios del guano. Estos consignatarios nacionales junto a sus socios extranjeros tuvieron a su cargo no menos de los 10 contratos de consignación celebrados entre 1849-1872 (Macera 1977, vol. 4, 129). Y entre 1862-1869, la Compañía Nacional de Consignatarios tuvo el monopolio de exportación de guano al mercado británico, logrando desplazar del negocio a la conocida casa extranjera Gibbs.

\section{Manuel Pardo y la creación del primer Banco de Crédito Hipotecario en el Perú}

El decreto dictatorial del 31 de enero de 1866, del Gobierno provisional de Mariano I. Prado, autorizaba la creación y organización de una sociedad privada con el título de "Banco de Crédito Hipotecario", cuyo objetivo era facilitar los préstamos a largos plazos sobre hipotecas de la propiedad territorial, y el reembolso de dichos préstamos y el pago de sus intereses por medio de 
un número determinado de anualidades (máximo 20 años). De esta forma, el banco se encargaría de resolver los problemas que la propiedad territorial y la agricultura arrastraban desde hace décadas, es decir, la ausencia de entidades que otorguen préstamos a largo plazo para invertir en el agro. $Y$ es que antes de la creación del Banco de Crédito Hipotecario, los préstamos de dinero se hacían por seis meses, con el interés de $1 \%$ mensual, y cuando se concedía a largo plazo, no pasaba de 3 a 4 años, con intereses de 12 , 14 y hasta de $18 \%$ anual. Estos préstamos a "corto plazo" imposibilitaban al agricultor a firmar dichos contratos, ya que le era difícil reunir el dinero en tan poco tiempo (6 meses-4 años) para pagar el capital e interés, ya que solo recibía una cosecha al año, además de esperar un tiempo para venderla (García Calderón 1868, 51).

Tabla 2. Primeros 20 accionistas del Banco de Crédito Hipotecario

\begin{tabular}{|l|c|l|}
\hline Accionistas & Acciones & Leyes que los favorecieron \\
\hline Buenaventura Elguera & 50,000 & \\
\hline Ramón Montero & 50,000 & \\
\hline Juan Manuel Montero (padre) & 50,000 & Manumisión de esclavos \\
\hline Manuel Montero & 50,000 & \\
\hline José Vicente Oyague y hno. & 40,000 & Consolidación, manumisión y consignación \\
\hline Pedro Denegri & 40,000 & Consolidación de la deuda interna y manumisión \\
\hline Delgado hnos. e hijos & 40,000 & Consolidación, manumisión y consignación \\
\hline Carlos G. Candamo & 40,000 & Consolidación, manumisión y consignación \\
\hline Juan M. Goyeneche y Gamio & 40,000 & \\
\hline José Canevaro e hijos & 40,000 & Consolidación y consignación \\
\hline Antonio Joaquín Ramos & 40,000 & Manumisión de esclavos \\
\hline Sescau, Valdeavellanos y Ca. & 40,000 & Consolidación y consignación de guano \\
\hline José Mansueto Canaval & 25,000 & Manumisión de esclavos \\
\hline Enrique Swayne & 20,000 & Manumisión \\
\hline José Domingo Castañeda & 20,000 & Consolidación \\
\hline José G Seacone & 20,000 & \\
\hline Julián de Zaracondegui & 19,000 & \\
\hline José de la Riva Agüero & 10,000 & \\
\hline Carlos de la Rva Agüero & 10,000 & \\
\hline Francisco García Calderón & 10,000 & \\
\hline 20 accionistas & Total & \\
\hline $\mathbf{6 5 4 . 0 0 0}$ & \\
\hline
\end{tabular}

Fuente: El Peruano (1866, N. ${ }^{\circ} 10$, t. 51), Quiroz (1987, 76-81 y 161-165) 
E1 Banco de Crédito Hipotecario pudo abrir sus puertas al público el 19 de noviembre de 1866, iniciando sus operaciones en la calle Mantas (hoy la primera cuadra del jirón Callao), cerca de la catedral de Lima y la plaza Mayor, con un capital mayor que el señalado por decreto del 31 de enero de ese mismo año. Años más tarde, en 1871, el capital del banco alcanzaba la suma de 3 000000 soles, con varios accionistas como soporte (ver tabla 2).

\section{La organización y administración del Banco de Crédito Hipotecario}

Según el artículo 23 del decreto del 31 de enero de 1866, el Banco de Crédito Hipotecario quedaría bajo la administración de un Consejo, compuesto por 5 directores miembros accionistas poseedores de 40 acciones, esto es 40000 soles, ya que el capital del Banco era de 1500000 soles, divididos en 1500 acciones, de 1000 soles cada una. El Consejo de Administración sería elegido por los accionistas en junta general. La gestión y representación del banco quedaría a cargo de un gerente general accionista por 10000 soles, elegido por el Consejo de Administración (El Peruano 1866, N. ${ }^{\circ}$ 53).

Las funciones del banco quedaron establecidas en el artículo 2 de los estatutos, las cuales consistían en emitir cédulas, títulos para cada préstamo hipotecario con un interés del $6 \%$ y $8 \%$ anual (estas cédulas se emitieron de los tipos de 100, 500 y 1000 soles, y su precio en el mercado fluctuó en un principio alrededor del $88 \%$ ), atender al servicio de esas cédulas pagando los intereses trimestralmente y amortizándolos semestralmente por medio de sorteo a la par, así como realizar ventas a comisión directamente o por medio de sus agentes, productos, maquinarias o útiles agrícolas, por cuenta de los mismos. En cuanto a la naturaleza del monto y condición de los préstamos que otorgaría el banco, estas serían no menor de 500 soles, y el valor del inmueble hipotecado, no menor de 2.000 soles. Dichos préstamos se otorgarían con la condición de que se utilicen únicamente para la compra de fundos, para la cancelación de hipotecas anteriores o para las mejoras productivas del fundo, según los artículos 13 y 19 de los estatutos del banco (El Peruano 1866, N. ${ }^{\circ}$ $53,14)$. La entidad, dentro de sus obligaciones con los accionistas, emitiría un informe explicando al detalle las operaciones, considerando las pérdidas o ganancias del banco realizadas al 31 de diciembre de cada año. Para ello, la Junta General de accionistas nombraría dos inspectores para realizar los 
estudios de las operaciones del banco entregadas al gerente general con el fin de redactar un informe final, leída luego por este a los accionistas de la junta.

\section{Las operaciones y balances del Banco de Crédito Hipotecario}

Las operaciones del banco durante su primer año de gestión fueron positivas, según el informe presentado por los inspectores Julián de Zaracondegui y Valentín Gil al gerente general del banco, José de la Riva Agüero. La memoria redactada por el gerente mostraba razones suficientes para justificar la existencia del banco. La propiedad, tanto rural como urbana, y la agricultura que décadas atrás no podían encontrar capitales a largo plazo, había recibido del banco, desde el 19 de noviembre de 1866 hasta el 31 de diciembre de 1867, la cantidad de 1261500 soles, de los que 746000 soles se habían entregado con hipoteca de fundos rústicos, y 515500 soles con hipoteca de fundos urbanos (El Nacional 1868, N. ${ }^{\circ} 715$ ). Según la lectura de la memoria del primer año de funcionamiento del banco, son los fundos rústicos los que perciben la mayor cantidad de cédulas, con el $59 \%$ del total entregadas por el banco para la modernización y el aumento de la producción agrícola (ver tabla 3).

Tabla 3. Primer balance del Banco de Crédito Hipotecario (1866-1867)

\begin{tabular}{|c|c|c|}
\hline $\begin{array}{c}\text { N. }{ }^{\circ} \text { de contratos } \\
\text { (prestatarios) }\end{array}$ & $\begin{array}{c}\text { Monto del préstamo } \\
\text { recibido }\end{array}$ & $\begin{array}{c}\text { Lugar del inmueble } \\
\text { y/o fundo hipotecado }\end{array}$ \\
\hline 54 & 926,900 & Lima \\
\hline 7 & 51,200 & Callao \\
\hline 4 & 213,000 & Ica \\
\hline 3 & 38,400 & La Libertad \\
\hline 2 & 9,000 & Arequipa \\
\hline 1 & 23,000 & Ancash \\
\hline 71 contratos & 1.261 .500 soles & 5 departamentos + Callao \\
\hline
\end{tabular}

Fuente: El Nacional (1868, N. $\left.{ }^{\circ} 715\right)$.

De acuerdo con los datos presentados en la tabla 3, 61 contratos de un total de 71 se realizaron con propietarios y agricultores del departamento de Lima y Callao. Esto representó el $85 \%$ del número de contratos realizados por el banco, recibiendo la cantidad de 978100 soles en cédulas hipotecarias, que significó el $77.5 \%$ del monto total prestado por el banco. El otro $22.5 \%$ del 
monto total prestado (283 400 soles) fue destinado a los departamentos de Ica, La Libertad, Arequipa y Áncash. Esto significa que el banco, con la apertura de sucursales en el resto del país, podía en los años posteriores haber elevado el número de contratos y beneficiarios, ya que, según el artículo 4 del decreto ministerial del 28 de agosto de 1866, el Banco estaba obligado a establecer sucursales en otras ciudades.

Más de un millón de soles fueron empleados, en tan solo un año, en las mejoras y modernización de las haciendas, contribuyendo al desarrollo de la agricultura de exportación. Y también fueron destinados a la redención de gravámenes anteriores, permitiendo a los propietarios adquirir el pleno dominio de ellos (ver tabla 4).

Tabla 4. Destino de préstamos realizados por el Banco de Crédito Hipotecario (1867)

\begin{tabular}{|c|c|c|}
\hline Destino & & Cantidad de inversión \\
\hline & que gravaban con el & \\
\hline Cancelación de & $11 / 4$ y $11 / 2 \%$ al mes & \\
\hline otras hipotecas & & \\
\hline & que gravaban con el & \\
\hline & $1 \%$ ala mes & \\
\hline & & \\
\hline Mejoras y & & \\
\hline modernización & Rústicos y urbanos & \\
\hline de los fundos & & \\
\hline & Total & 1.261 .500 \\
\hline
\end{tabular}

Fuente: El Nacional $\left(1868\right.$, N. $\left.^{\circ} 715\right)$

Esto demuestra que los préstamos realizados por el Banco de Crédito Hipotecario, que también obligaba al prestatario a pagar $1 \%$ de interés mensual (12\% anual), resultaban mucho más ventajosos para el agricultor que los contratos de igual gravamen celebrados con otras instituciones y particulares. Las ventajas - he ahí la importante labor del banco- radicaban en el largo plazo que concedía el banco (20 años) a los agricultores para amortizar los préstamos, y la otra ventaja era que el cobro de las anualidades del banco comprendía el interés y la amortización del capital juntos.

Por consiguiente, de los 1261500 soles que prestó el banco a los agricultores y propietarios, 544130 soles fueron destinados para la cancelación de 
otras hipotecas. Esto significa que el $43 \%$ del monto total que prestó el banco durante su primer año de gestión sirvió para la liberación de los agricultores y propietarios de sus hipotecas con otras entidades y particulares que prestaban dinero con intereses de 1, 11/4 y 11/2\% mensual.

Las memorias del banco de los años de 1869 y 1870 no fueron publicadas en los diarios ni periódicos de la época, sin embargo, las que están comprendidas entre los años de 1878-1881 fueron halladas en el depósito de publicaciones de la Biblioteca Central de la Universidad Nacional Mayor de San Marcos, y otro grupo de documentos relacionados al banco fueron hallados en el depósito del Fondo Reservado de la misma casa de estudios. En la memoria del banco de 1881, se halló un cuadro donde se especifica la cantidad exacta (en cédulas y soles) que el banco prestó durante todos los años de su gestión desde, 1866 hasta 1880 (ver tabla 5).

Tabla 5. Cuadro de los estados de los préstamos del Banco de Crédito Hipotecario (1881)

\begin{tabular}{|l|c|c|c|c|c|c|c|}
\hline $\begin{array}{l}\text { Préstamos } \\
\text { hechos } \\
\begin{array}{l}\text { en los } \\
\text { años (en } \\
\text { cédulas) }\end{array}\end{array}$ & $1866-1867$ & 1868 & 1869 & 1870 & 1871 & 1872 & 1873 \\
\cline { 2 - 8 } & $1,261,500$ & 994,000 & $1,314,200$ & $2,356,400$ & $1,245,200$ & $3,001,100$ & $3,120,000$ \\
\cline { 2 - 8 } & 1874 & 1875 & 1876 & 1877 & 1878 & 1879 & 1880 \\
\hline
\end{tabular}

Fuente: Memorias del Banco de Crédito Hipotecario (1881)

De acuerdo con los datos de la tabla 5, se puede observar que en el tercer año (1869) de funcionamiento del banco la cifra de préstamos aumentó a 1 314200 soles en cédulas, superando las cifras de los dos años anteriores, debido a la confianza que el Gobierno de José Balta y el Congreso de la República depositaron en el Banco de Crédito Hipotecario al ratificar la vigencia de la autorización de las bases del banco dictadas por el decreto del 31 de enero de 1866. Estas medidas permitieron que los propietarios y agricultores confiaran y tomaran los créditos que otorgaba el banco, y el público en general a tomar las cédulas en el mercado de vales y cédulas. El 4 de enero de 1869, el presidente de la república José Balta, el ministro de Hacienda Nicolás de Piérola, y el presidente del Senado José Rufino Echenique decidieron ratificar el funcionamiento del banco.

Según los estimados de Pablo Macera (1977, vol. 4, 128) los capitales entregados por el sector exportador (guano) - a través del Estado- a la agricultura costeña, entre los años de 1845 a 1855, fue de 15000000 de soles. 


\begin{tabular}{llr}
1850 & Consolidación interna & 8000000 \\
1854 & Manumisión de esclavos & 7000000 \\
\hline $1845-1854$ & Total de transferencia & 15000000
\end{tabular}

Si se compara la cifra proporcionada por Macera (1977) con la cantidad entregada por el Banco de Crédito Hipotecario, entidad privada creada exclusivamente para financiar el desarrollo agrícola y la propiedad territorial, apreciaríamos la enorme labor crediticia del banco al transferir 14850200 en soles y cédulas a la agricultura costeña de exportación, desde 1866 hasta 1880, según las memorias del Banco de Crédito Hipotecario. Considerando las diferencias entre los grandes ingresos del Estado generados por la exportación del guano — según Heraclio Bonilla (1974), el valor total de las exportaciones registró 750000000 de soles-, y comparándolas con las del capital del banco cuyos accionistas lograron acumular solo 1500000 soles, se comprobaría la gran labor que cumplió el banco. La cantidad de 14850200 de soles y cédulas hipotecarias permitió el aumento de la producción agrícola, que se vio reflejado en las exportaciones de algodón y azúcar. La tabla 6 y el gráfico 1 muestran el aumento de las exportaciones de algodón y azúcar entre los años 1867-1870. El capital del banco aumentaría para el año 1871 en 3000000 de soles debido a la gran demanda crediticia de los agricultores y propietarios.

TABLA 6. Exportaciones de algodón y azúcar y su relación con los préstamos del Banco de Crédito Hipotecario destinados a los agricultores (1861-1871)

\begin{tabular}{|c|c|c|c|}
\hline Año & $\begin{array}{c}\text { Préstamos en cédulas y soles del Banco } \\
\text { Capital a la agricultura }\end{array}$ & $\begin{array}{l}\text { Exportaciones } \\
\text { Algodón }\end{array}$ & $\begin{array}{c}\text { Exportaciones } \\
\text { Azúcar }\end{array}$ \\
\hline 1861 & & 22,122 & 4,077 \\
\hline 1862 & & 15,208 & 5,000 \\
\hline 1863 & & 17,009 & 1,000 \\
\hline 1864 & & 16,469 & 16,416 \\
\hline 1865 & & 33,018 & 4,724 \\
\hline 1866 & Apertura del Banco el 19 de noviembre & 41,317 & 14,000 \\
\hline 1867 & $1,261,500$ & 126,299 & 11,000 \\
\hline 1868 & 994,000 & 189,324 & 26,749 \\
\hline 1869 & $1,314,200$ & 78,109 & 24,588 \\
\hline 1870 & $2,356,400$ & 95,109 & 70,474 \\
\hline 1871 & $1,245,200$ & 194,577 & 131,091 \\
\hline
\end{tabular}

Fuente: Jean Piel (1995, 332 y 338), Banco de Crédito Hipotecario (1881) 
GRÁFICo 1. Exportaciones en libras esterlinas de algodón y azúcar (1861-1871)

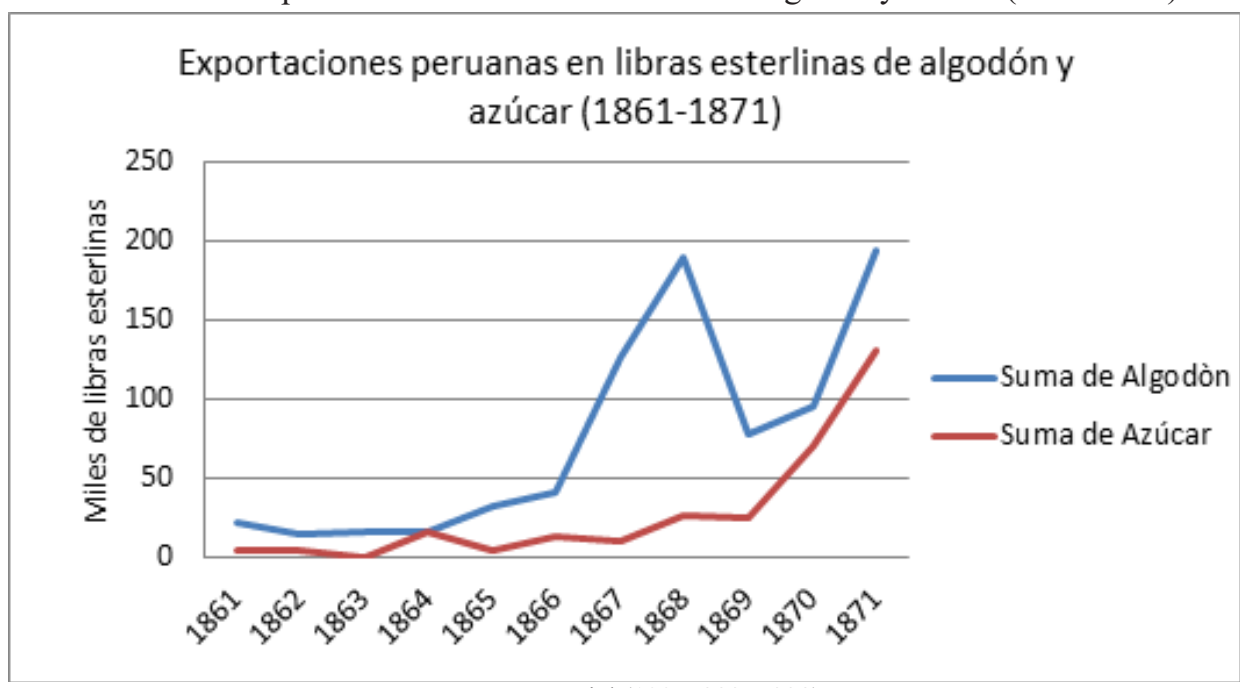

Fuente: Jean Piel (1995, 332 y 338)

\section{Conclusiones}

Esta gran masa de capital que el Banco de Crédito Hipotecario destinó a la agricultura, solo en 1867, se vio reflejado en el aumento de las exportaciones de caña de azúcar y algodón en 1868. El Perú, ese último año, registró 189324 libras esterlinas en exportaciones de algodón, cuando en 1862 las exportaciones de algodón apenas habían registrado 15208 libras esterlinas. En cuanto a las exportaciones de azúcar, en 1868, se registró 26749 libras esterlinas, cuando en 1863 apenas se había registrado 1000 libras esterlinas.

En su segundo año, en 1868, el banco destinó un total de 994000 soles a los propietarios y agricultores. Era una cantidad inferior a la de su primer año de funcionamiento. Esto debido a la inseguridad que tenían los propietarios y agricultores, ya que existía el temor del cierre del banco por la "revolución" emprendida por Pedro Diez Canseco, quien dispuso por decreto del 14 de octubre de 1867 la anulación de todos los actos del Gobierno dictatorial de Mariano I. Prado. Sin embargo, el banco continuó en sus funciones. Nuevamente fueron propietarios y agricultores de Lima los que obtuvieron mayor beneficio al recibir la cantidad de 712400 soles; le sigue Ica, con 160 200 soles; y luego Arequipa y Áncash, con 121400 soles en cédulas. Para 1869, las exportaciones de azúcar mantuvieron su volumen respecto a 1868. 
En el Perú, a partir de 1870, se inicia el despegue impresionante de las exportaciones de azúcar y algodón al mercado externo, y ello coincide con los años que el Banco de Crédito Hipotecario otorgó la mayor cantidad de préstamos en soles y cédulas a los propietarios y agricultores. En 1870, el banco logró destinar a los agricultores, en su mayoría de la costa peruana, la cantidad de 2356400 soles en cédulas, y ese mismo año las exportaciones agrícolas registraron un alza de 95109 de libras esterlinas en el caso de algodón, y las exportaciones de azúcar registraron 70474 de libras esterlinas. Para 1871, el banco prestó la cantidad de 1245200 soles en cédulas, y ese mismo año las exportaciones de azúcar y algodón logran superar la cifra de los años anteriores; se logró exportar algodón por la cantidad de 194577 en libras esterlinas, y el azúcar por la cantidad de 131091 en libras esterlinas.

Entre 1872 y 1873, el banco destinó la mayor cantidad de préstamos durante los años de su existencia. En 1872, el Banco de Crédito Hipotecario entregó a los agricultores la cantidad de 3001100 soles en calidad de préstamos para la inversión en sus propiedades y fundos agrícolas; y en 1873, se entregó 3120000 soles en cédulas, siendo la cifra más alta que el banco haya entregado durante todos los años de su existencia. Además, 1873 fue el último año en que la actividad bancaria gozaría de completa libertad, ya que el 18 de diciembre de 1873 el Gobierno civilista de Manuel Pardo decide intervenir en la actividad bancaria, y ello repercutió de manera negativa en las actividades del banco. Así, desde 1874 hasta 1880, los préstamos realizados por el banco bajaron de manera estrepitosa, entregando en total 1557800 soles en cédulas, durante los 7 años que van desde 1874 hasta 1880. De acuerdo con su memoria del año 1881, el Banco de Crédito Hipotecario habría destinado, desde 1866 (año de su fundación) hasta 1880, un total de 14850200 soles en cédulas hipotecarias a los propietarios y agricultores para la inversión en sus fincas y haciendas. 


\section{Referencias bibliográficas}

Banco de Crédito Hipotecario del Perú. 1873. Estatutos del Banco de Crédito Hipotecario, aprobados por Supremo Decreto de 16 de agosto de 1866. Lima: Imprenta de J. Francisco Solís.

Banco de Crédito Hipotecario del Perú. 1883. Respuesta que da el Banco de Crédito Hipotecario al folleto publicado por el comité de sus deudores. Lima: Imp. del Teatro. Biblioteca Central F. Reservado Col. F. 146/1.

Basadre, J. 2005 Historia de la República del Perú [1822-1933]. Tomos del I-VIII. Lima: El Comercio S. A.

Bonilla, H. 1974. Guano y burguesía en el Perú. Lima: Instituto de Estudios Peruanos.

Camprubi, C. 1957. Historia de los bancos en el Perú: 1860-1879. Lima: Lumen. S. A.

Contreras, C. 2010. El legado económico de la independencia en el Perú. Documento de trabajo No. 301. Lima: Pontificia Universidad Católica del Perú. https://bit.ly/3itUe85

Contreras, C. y Cueto, M. 2000. Historia del Perú contemporáneo. Lima: Fondo Editorial de la Pontificia Universidad Católica del Perú, Instituto de Estudios Peruanos.

García Calderón, F. 1868. Estudios sobre el Banco de Crédito Hipotecario y las leyes de hipoteca. Lima: Imprenta José Noriega.

Hunt, S. 2011. Guano y crecimiento en el Perú del siglo XIX. En La formación de la economía peruana. Distribución y crecimiento en la Historia del Perú y América Latina. Lima: Fondo Editorial de la Pontificia Universidad Católica del Perú, Banco Central de Reserva del Perú, Instituto de Estudios Peruanos.

Macera, P. 1977. Las plantaciones azucareras andinas 1821-1875. En Trabajos de historia. Tomo IV. Lima: Instituto Nacional de Cultura.

Pardo y Lavalle, M. 1861. El crédito hipotecario en Francia y Chile en 1859 y 1860. Revista de Lima. Tomo IV.

Quiroz, A. 1987. La deuda defraudada. Consolidación de 1850 y dominio económico en el Perú. Lima: Instituto Nacional de Cultura.

Tantaleán, J. 2011. La gobernabilidad y el leviatán guanero. Desarrollo, crisis y guerra con Chile. Lima: Banco Central de Reserva del Perú, Instituto de Estudios Peruanos. 


\section{Fuentes primarias}

Fondo Reservado de la Universidad Nacional Mayor de San Marcos:

Sala de Manuscritos y Libros: colección manuscritos

Colección de folletos antiguos

Biblioteca Nacional del Perú. Sala de Hemeroteca

El Peruano 1866, N. ${ }^{\circ} 10,13,53$

El Nacional 1868, 1869, 1870, 1871 